\title{
Comparison of the Effectiveness of Intraarticular Ozone Therapy and Platelet Rich Plasma Treatment in Patients with Knee Osteoarthritis
}

\section{Ümit Yalçın *}

Physical Medicine and Rehabilitation, Medicana International İstanbul Hospital, Beylikdüzü, İstanbul, Türkiye

*Corresponding Authors: Ümit Yalçı; drumitftr07@gmail.com

Received 08 March 2020;

Accepted 28 March 2020;

Published 01 April 2020

\begin{abstract}
Background: Platelet rich plasma (PRP) has been applied for a long time in osteoarthritis (OA). Although there are studies about PRP that examining the effectiveness with agents such as hyaluronic acid and corticosteroid, there are few published literature comparing with ozone therapy (OT). The aim of this study is to compare the pain severity and functional status of OA patients undergoing intraarticular ozone and PRP injections. Methods: In a study which is made as prospective, randomized controlled study (RCS), 49 patients were included the study. In the first group $(\mathrm{n}=24)$ OT, in the second group $(\mathrm{n}=25)$ PRP injections were administered intraarticularly 3 times in total with one week intervals. Visual pain scale (VAS) and severity of pain were compared with Western Ontario McMaster Osteoarthritis Index (WOMAC). $\underline{\text { Results: }}$ In the PRP group, WOMAC pain, physical function and WOMAC total score were significantly lower than the OT group ( $p<0.05)$. Although VAS score decreased significantly $(\mathrm{p}<0.05)$ after treatment in both groups compared to pretreatment, the VAS score in the PRP group was significantly $(\mathrm{p}<0.05)$ lower than the OT group after treatment. Conclusion: Our study contributes to the literature in terms of limited publication about OT. However, this study shows that the results of PRP treatment are superior to OT in the treatment of knee OA.
\end{abstract}

Keywords: Osteoarthritis, arthrose, Ozone Therapy, Ozone, Platelet Rich Plasma, Pain, gonarthrose, Growth factor.

\section{Introduction}

Osteoarthritis (OA) is a complex process involving cartilage degeneration, synovitis, subchondral bone formation, capsular hypertrophy, and soft tissue ruptures involving the entire joint, as well as inflammatory mediators. Although OA can affect all joints, the most commonly affected joint is the knee joint. Due to pain and limitation of movement, it prevents the daily activities of the patient and reduces the quality of life. The incidence of OA increases with age ${ }^{[1,2]}$. Some conditions that cause pain in patients with OA; joint effusion, bursitis and spasm in the surrounding muscle tissues. Because there are no nociceptive receptors, hyaline articular cartilage is not a factor for pain. In OA, pain is caused by a combination of multifaceted etiologies both inside and outside the joint ${ }^{[3-6]}$. Joint pain in patients with OA results from the activation of $\mathrm{A}-\delta$ mechanoreceptors and C-polymodal nerve endings in synovium and surrounding structures, except joint cartilage in the knee ${ }^{[7]}$. The perception of pain is carried through the spinal nerves and occurs in the thalamus and somatosensory cortex. Suppression $\mathrm{P}$ is released from myelin-free sensory neurons in the synovium. In patients with $\mathrm{OA}$, suppression $\mathrm{P}$ was determined in the synovium and synovial fluid, and this substance may play a role in the activation of synovial and inflammatory cells, secretion and strengthening of inflammatory mediators ${ }^{[8]}$. The pathogenesis of the disease is attributed to the deterioration of the balance between cartilage matrix synthesis and destruction. In synovial fluid analysis, proteolytic enzymes, reactive oxygen radicals and lipid peroxidation products were determined to be responsible for cartilage matrix destruction. As the degeneration progresses, the ratio of hyaluronic acid (HA), molecular weight, viscoelasticity, shock absorber and lumbrikan property in synovial fluid decreases ${ }^{[9,10]}$. Treatment methods in knee OA are various and patient education, rest, preventive precautions, pharmacological treatment, physical therapy and surgical treatment methods can be used alone or in combination according to the stages of the disease ${ }^{[11]}$. Surgical treatment is preferred in patients with advanced degeneration, while conservative methods are preferred in the early stages. Intra-articular injections positively affect pain and functional status in gonarthrosis ${ }^{[12]}$. HA, radioisotopes, botilinumtoxin $\mathrm{A}$, tropisetron, and tanezumab are agents that are used to rapidly infiltrate the knee and improve the intra-knee biochemical structure by reducing the pain and 
improving the intraarticular damage by regeneration. Although many studies have been published examining the efficacy of these agents, no clear conclusions have been reached as to how effective they are ${ }^{[13,14]}$. The use of agents containing growth factors of autologous origin is therefore becoming increasingly common. PRP is a platelet-rich plasma fraction in the upper part of autologous blood. It is a new treatment option in modern medicine called "ortho biologicals". The goal of this treatment is to stimulate the body's ability to repair and regenerate. Today, it is of great interest as a safe, non-invasive biological treatment area for OA and musculoskeletal repair. PRP was centrifuged to the patient's own blood; active, platelet-rich part is obtained by separation. The resulting material is applied to the damaged tissue by injection. In PRP, it is aimed to stimulate bone and soft tissue repair by introducing autologous platelets at the suprafysiological concentration to the damaged tissue. PRP is a promising treatment option for future regenerative therapies due to its ease of preparation, administration and reliability ${ }^{[15,16]}$. Intra-articular ozone is a long-term treatment; however, the number of literature on this subject is very limited. It is thought to increase blood flow and oxygenation in tissues with OT, inflammation and pain and provide better joint mobility by removing metabolic wastes in the affected joints. Again, it has anti-inflammatory, immunomodulatory, anti-edemic and antioxidant effects. Studies have shown that intraartricular OT is associated with decreased pain and improved quality of life in patients with knee OA. Intraartricular OT is a minimally invasive and well-tolerated procedure in patients with insufficient clinical response to conservative treatments or with physiotherapy contraindicated ${ }^{[17-}$ ${ }^{19]}$. In this study, we aimed to compare the pain and functional effects of intraarticular PRP and OT in knee OA.

\section{Materials and Methods}

In this study, 50 patients who were admitting to the physical medicine and rehabilitation clinic between July 2019 and December 2019 with knee pain and diagnosed as stage 2-3 Knee OA according to Kellgren-Lawrence classification were included. In this prospective study, patients were randomly divided into two groups. In the first group, intraarticular ozone was injected for a total of 3 sessions one week apart and PRP was injected in the second group. Each patient before and 1 month after treatment was evaluated with VAS score in terms of pain, with WOMAC score in terms of functional. Informed patients about the study, informed consent of the patients and ethical committee approval of our study were obtained. The individual rights of the patients were respected throughout the study, adhering to the principles of the Helsinki Declaration. Inclusion criteria were; According to the KellgrenLawrence classification, to be grade 2 or 3 primary Knee OA, to be in between the ages of 35-65, and NSAIDs did not relieve pain. Patients with stage 1 or 4 knee OA, who had previously received intra-articular injection treatment such as steroids, HA, PRP, OT, had a history of previous knee surgery, autoimmune disease, thrombocytopenia, a history of malignancy, and active infection were not included in the study.

\section{Procedures:}

The first group received OT once a week for a total of 3 weeks under sterile conditions. After local anesthesia was provided with 2 $\mathrm{ml} 2 \%$ lidocaine by the aseptic technique on the lower outer edge of the patella, the joint space was entered with a $22 \mathrm{G}$ needle and $15 \mathrm{ml} 20 \mu \mathrm{g} / \mathrm{ml}$ OT was applied and the knee joint was flexed and extension movements were dispensed within the joint. The second group received PRP treatment once a week for a total of 3 weeks. PRP was prepared and administered in all patients under the same conditions. A total of $10 \mathrm{cc}$ of peripheral blood from the antecubital region was taken into $3.2 \%$ sodium citraticeren tubes. Samples were centrifuged at $3200 \mathrm{rpm}$ for 10 minutes at room temperature (Eppendorfcentrifuge 5702, Hamburg Germany). The resulting 2 $\mathrm{ml}$ PRP was injected into the joint after sterile conditions with local anesthesia with $2 \mathrm{ml} 2 \%$ lidocaine by aseptic technique from the lower outer edge of the patella.

\section{Evaluation Criteria:}

Pain assessment: VAS was used for pain assessment. A $10 \mathrm{~cm}$ segmented line was used to determine the severity of pain. Zero value indicates absence of pain and 10 value indicates intolerability of pain. The measured value was recorded in the patient follow-up form.

Functional Assessment: Functional assessment was performed with WOMAC. In this index, pain, stiffness and difficulties in daily living activities of the patients in the last 48 hours are questioned using a five point likert scale. The total score is $0-20$ for pain, $0-8$ for stiffness, $0-68$ for difficulties in daily living activities. The lower the score, the better the functional level, the higher the scores indicate that the high disease activity. The Turkish validity and reliability of the index have shown by Tüzün et al. ${ }^{[20]}$.

Statistical Methods: Mean, standard deviation, median, minimum, maximum value were used for descriptive statistics. The distribution of variables was checked with kolmogorov-simirnov test. Mann-Whitney $\mathrm{U}$ test was used for the comparison of quantitative data. Wilcoxon test was used for the repeated measurement analysis. Chi-Square test was used for the comparison of the qualitative data. SPSS 26.0 was used for statistical analyzes. Statistical significance was defined as $p<0.05$

\section{Results}

The age and gender distribution of the patients in the ozone and PRP treatment groups did not differ significantly $(p>0.05)$. (Table 1)

WOMAC pain score decreased significantly $(\mathrm{p}<0.05)$ after treatment in both groups compared to pretreatment. The WOMAC pain score was significantly $(\mathrm{p}<0.05)$ lower in the PRP group after treatment than in the OT group. (Table 1)

WOMAC stiffness score decreased significantly $(\mathrm{p}<0.05)$ after treatment in both groups compared to pretreatment. WOMAC hardness score decrease did not show significant $(\mathrm{p}<0.05)$ difference after treatment in OT and PRP treatment groups. (Table 1)

WOMAC physical function score decreased significantly $(\mathrm{p}$ $<0.05$ ) after treatment in both groups compared to pretreatment. In the PRP group, WOMAC physical function score after treatment was significantly lower than the OT group. (Table 1)

In both groups, WOMAC total score decreased significantly $(\mathrm{p}<0.05)$ after treatment compared to pretreatment. The WOMAC total score was significantly lower in the PRP group after treatment than in the OT group. (Table 1)

In both groups, VAS score decreased significantly $(\mathrm{p}<0.05)$ after treatment compared to pretreatment. The VAS score in the PRP group was significantly lower than the OT group $(\mathrm{p}<0.05)$. (Table 1) 
Table 1

\begin{tabular}{|c|c|c|c|c|c|c|c|c|c|c|c|}
\hline \multirow{3}{*}{$\begin{array}{l}\text { Age } \\
\end{array}$} & & \multicolumn{4}{|c|}{ Ozone Treatment } & \multicolumn{4}{|c|}{ PRP Treatment } & & \\
\hline & & \multicolumn{3}{|c|}{ Mean \pm sd $/ \mathrm{n}-\%$} & \multirow{2}{*}{$\begin{array}{l}\text { Median } \\
54,0\end{array}$} & \multicolumn{3}{|c|}{ Mean \pm sd/n- $\%$} & \multirow{2}{*}{$\begin{array}{l}\text { Median } \\
55,0\end{array}$} & & \\
\hline & & 53,2 & \pm & 7,7 & & 53,6 & \pm & 8,2 & & 0,826 & $\mathrm{~m}$ \\
\hline \multirow{2}{*}{ Gender } & Female & 12 & & $50,0 \%$ & & 12 & & $48,0 \%$ & & \multirow{2}{*}{0,889} & \multirow{2}{*}{$\mathrm{X}^{2}$} \\
\hline & Male & 12 & & $50,0 \%$ & & 13 & & $52,0 \%$ & & & \\
\hline \multicolumn{12}{|l|}{ WOMAC Pain } \\
\hline Before Treatment & & 12,0 & \pm & 3,7 & 12,0 & 11,3 & \pm & 3,6 & 10,0 & 0,501 & $\mathrm{~m}$ \\
\hline After Treatment & & 7,0 & \pm & 3,3 & 6,5 & 1,9 & \pm & 1,5 & 2,0 & 0,000 & $\mathrm{~m}$ \\
\hline Before/After Difference & & 5,0 & \pm & 4,6 & 3,0 & 9,4 & \pm & 3,7 & 9,0 & 0,001 & $\mathrm{~m}$ \\
\hline İntra Group Difference & & $\mathbf{0 , 0 0 0}$ & & & w & $\mathbf{0 , 0 0 0}$ & & & w & & \\
\hline \multicolumn{12}{|l|}{ WOMAC Hardness } \\
\hline Before Treatment & & 2,2 & \pm & 0,9 & 2,0 & 1,9 & \pm & 1,2 & 2,0 & 0,444 & $\mathrm{~m}$ \\
\hline After Treatment & & 0,7 & \pm & 0,6 & 1,0 & 0,4 & \pm & 0,6 & 0,0 & 0,116 & $\mathrm{~m}$ \\
\hline Before/After Difference & & 1,5 & \pm & 0,9 & 1,0 & 1,5 & \pm & 1,0 & 2,0 & 0,892 & $\mathrm{~m}$ \\
\hline İntra Group Difference & & 0,000 & & & w & 0,000 & & & w & & \\
\hline \multicolumn{12}{|c|}{ WOMAC Physical Funcitons } \\
\hline Before Treatment & & 40,2 & \pm & 9,2 & 38,0 & 40,4 & \pm & 11,2 & 44,0 & 0,944 & $\mathrm{~m}$ \\
\hline After Treatment & & 9,9 & \pm & 5,9 & 10,0 & 5,8 & \pm & 5,7 & 4,0 & 0,011 & $\mathrm{~m}$ \\
\hline Before/After Difference & & 30,3 & \pm & 8,9 & 30,0 & 34,6 & \pm & 12,9 & 38,0 & 0,258 & $\mathrm{~m}$ \\
\hline İntra Group Difference & & $\mathbf{0 , 0 0 0}$ & & & w & $\mathbf{0 , 0 0 0}$ & & & w & & \\
\hline \multicolumn{12}{|l|}{ WOMAC Total } \\
\hline Before Treatment & & 56,6 & \pm & 12,4 & 54,7 & 55,9 & \pm & 14,1 & 58,3 & 0,936 & $\mathrm{~m}$ \\
\hline After Treatment & & 18,2 & \pm & 6,4 & 20,3 & 10,0 & \pm & 9,6 & 7,3 & 0,000 & $\mathrm{~m}$ \\
\hline Before/After Difference & & 38,4 & \pm & 9,7 & 40,1 & 45,8 & \pm & 16,6 & 52,1 & 0,136 & $\mathrm{~m}$ \\
\hline İntra Group Difference & & $\mathbf{0 , 0 0 0}$ & & & w & $\mathbf{0 , 0 0 0}$ & & & $\mathrm{w}$ & & \\
\hline \multicolumn{12}{|l|}{ VAS } \\
\hline Before Treatment & & 6,0 & \pm & 1,7 & 6,0 & 6,8 & \pm & 1,0 & 7,0 & 0,069 & $\mathrm{~m}$ \\
\hline After Treatment & & 3,1 & \pm & 1,3 & 3,0 & 1,1 & \pm & 0,8 & 1,0 & 0,000 & $\mathrm{~m}$ \\
\hline Before/After Difference & & 2,9 & \pm & 1,6 & 3,0 & 5,7 & \pm & 1,3 & 6,0 & 0,000 & $\mathrm{~m}$ \\
\hline İntra Group Difference & & $\mathbf{0 , 0 0 0}$ & & & w & 0,000 & & & w & & \\
\hline
\end{tabular}

${ }^{\mathrm{m}}$ Mann-whitney u test $/{ }^{\mathrm{w}}$ Wilcoxon test $/{ }^{\mathrm{X}^{2}}$ Chi-square test

\section{Discussion}

Due to increasing obesity and prolonging the life expectancy in the society, the incidence of knee OA is increasing. In recent studies, symptomatic OA has been reported in $13 \%$ of people in the community over 60 years of age ${ }^{[21]}$. Until recently, it has been recommended that therapies should be aimed at preventing the progression of the disease at an early stage, since the damage caused by the knee OA within the joint is irreversible. The discovery that growth factors, stem cells and various cytokines have a positive effect on regeneration has destroyed this taboo. However, it remains a mystery that which agent should be used for which patient, and how much ${ }^{[22]}$. Different treatment options are applied according to stages in knee OA. Intra-knee injections, physiotherapy and non-steroidal anti-inflammatory drugs are commonly used conservative treatment methods. The use of intraknee injections in clinical practice is increasing. PRP is the easiest agent to obtain compared to other autologous biological agents. PRP; include factors such as platelet-derived insulin-like growth factor, fibroblast growth factor, platelet-derived growth factor, epidermal growth factor, vascular endothelial growth factor. These factors suppress inflammation, stimulate the removal of necrotic cells and help tissue reconstruction. Because of these properties, not only in orthopedic pathologies, but in many different areas of self-use of this agent has found many different disciplines have reported very successful results ${ }^{[23]}$. With the effect of growth factors, PRP stimulates local stem cells and activates restorative cells in the bone marrow by circulation. PRP also increases the tenocyte proliferation at the site of injury by providing revascularization with the growth factors it contains and plays an active role in increasing the collagen expression in the tenocytes ${ }^{[24]}$. PRP is available with ready-made kits or manually. Anitua et al. Reported that platelet counts above $300,000 / \mu 1$ in PRP were effective ${ }^{[25]}$. In another in vitro study, it is stated that platelet concentration is most effective when it is 2.5 times higher than basal platelet count ${ }^{[26]}$. The prepared PRP is activated by adding bovine or human thrombin or calcium chloride. Growth factors and cytokines are released by the formation of platelet gel from activated PRP. Some authors have used PRP without activating it [27]. There is no consensus on the ideal volume, frequency of administration, period of administration, or platelet activation for the administration of PRP ${ }^{[28]}$. In our study, PRP was prepared with ready kit (PRP S \& M, STR Bio Medical Technologies, Çorum / Turkey). In the analysis of the prepared PRP, it was found that it was 5 times higher than the platelet count in the peripheral blood and calcium chloride was not added to the prepared PRP for 
activation. In a study comparing PRP and hyaluronic acid HA injections with 175 patients by Güler et al., they reported that they received 3 injections of $2 \mathrm{ml}$ plasma and buffycoat compound after the procedure in a total of one week apart, and achieved a significant improvement in PRP and VAS scores compared to HA patients. ${ }^{[29]}$. In a study comparing PRP and HA injections with 120 patients by Cerza et al., they administered a total of $5,5 \mathrm{ml}$ of plasma and buffycoat compound to 4 injections one week apart, and reported that they achieved more improvement in pain and function with PRP ${ }^{[30]}$. Ozone $(\mathrm{O} 3)$ is an unstable, strong oxidizing gas consisting of three oxygen atoms with antiseptic, immunomodulatory, analgesic and anti-inflammatory properties. Ozone, a colorless, pungent gas, is also a chemical derivative of oxygen ${ }^{[31,32]}$. The first use of ozone in medicine was carried out by Fisch in 1932. In 1935, Payer examined the contribution of OT to surgical treatment. Today, OT can be used in different branches with different indications. In inflammatory and degenerative diseases related to the musculoskeletal system, the effects of ozone injection on the activation of anti-inflammatory, anti-oxidative capacity and immunomodulating effects are utilized. Clinical studies evaluating the effects of ozone on the musculoskeletal system are increasing. Ozone therapy is increasingly used in musculoskeletal disorders due to reduced inflammation, rapid pain control and associated early mobilization effects ${ }^{[33,34]}$. Dissolved ozone in body fluids reacts immediately with antioxidants and polyunsaturated fatty acids, resulting in fast-acting (short half-life) reactive oxygen compounds (ROS) (most importantly $\mathrm{H} 2 \mathrm{O} 2$ ) and lipid peroxidation products (LOPs) with a longer half-life. In the first phase, $\mathrm{H} 2 \mathrm{O} 2$ spreads to the cell cytoplasm and acts as a trigger. It causes different chemical pathways depending on the cell types it affects. Reactive oxygen products act as messengers and are removed by antioxidants in a very short time, but the complex pharmacodynamics of lipid peroxidase products minimize their potential toxicity and enable them to become long-term messengers ${ }^{[35]}$. Ozone is soluble in the water component of synovial fluid by intraarticular application and reacts with biomolecules to lead to the formation of ROS and LOP. The result is inhibition of the release of pro-inflammatory cytokines and proteolytic enzymes, as well as reduction of inflammation by the release of transforming growth factor beta 1(TGF-b1) and interleukin 10(IL-10), which are immunosuppressive cytokines. Increased TGF-b1 regulates the expression of integrins and stimulates the synthesis of matrix proteins such as collagen and glycosaminoglycans. Chondrocyte and matrix proliferation stimulated by $\mathrm{H} 2 \mathrm{O} 2$ lead to increased articular cartilage synthesis ${ }^{[36]}$. Intraarticular applications can be preferred in knee joint, hip, shoulder, ankle and other peripheral joints. It can be used in inflammatory / degenerative diseases and after sports injuries. Although there is no consensus on ozone / oxygen concentrations and doses, weekly injections of 5-20 mL in the knee and shoulder joints and 1-2 $\mathrm{mL}$ in the smaller joints have been recommended in 10-20 $\mu \mathrm{g} / \mathrm{mL}$ concentrations ${ }^{[37]}$. Similarly, in our study, we applied ozone at a dose of $15 \mathrm{ml} 20 \mu \mathrm{g} / \mathrm{ml}$. It has been reported that intraartricular OT is a minimally invasive and well tolerated treatment that reduces pain and improves quality of life in knee OA patients with insufficient clinical response to conservative treatments or where physiotherapy is contraindicated ${ }^{[8,38]}$. There are also different recommendations in the literature regarding döşe and frequency. The Italian Association of OzoneOxygen Therapy (SIOOT) recommends the slow application of a smaller volume of ozone than the old method of high volume. Five injections are recommended at weekly intervals. Knee flexion and extension after intra-articular injection provides better distribution of the gas ${ }^{[39]}$. However, there are many different studies with different doses and different number of sessions; In a study which was made by Camelia et al. $2-5 \mu \mathrm{g} / \mathrm{ml}$ and $40-50 \mathrm{ml}$ of ozone were applied to all patients in 12 sessions ${ }^{[8]}$. In a study which is made by Rabago et al. ultrasound-guided ozone or hypertonic dextrose in the joint was given ${ }^{[40]}$. Eighty patients with mild to moderate knee OA were randomized into two groups as ozone and dextrose group. The injections were administered 3 times with an interval of 10 days. Pain scores and WOMAC scores were significantly reduced in both groups. In another study; $80 \%$ treatment response was achieved with $10 \mathrm{ml}$ intraarticular OT 3 times in total at $30 \mu \mathrm{g} / \mathrm{ml}$ in the zero, first and second months and the effect was reported to last for 6 months. In the same study, it was shown that ozone was more effective in reducing pain, stiffness and physical disability than methylprednisolone $(40 \mathrm{mg})$ injection, and when both were given together, it was more effective than both treatments separately ${ }^{[19]}$. In a study in which a total of 12 sessions of $20 \mu \mathrm{g} / \mathrm{ml}$ ozone injections were performed twice a week, the mean NRS scores were found to be 8.02 at the beginning and 4.86 on the 10th month ${ }^{[7]}$. In addition to the studies comparing OT and HA applications, both are available together. Cardelli et al. as a result of their study investigated the effects of ozone and HA combination on hip OA, $30 \%$ increase in functionality and significant decrease in pain levels in all patients in the first month after treatment ${ }^{[41]}$. Xufeng et al. in a study performed in 76 patients with knee OA, half of the patients were treated with intraarticular OT, the other half were administered with oral glucosamine and celecoxib after pain and functional treatment, and the ozone-treated group showed statistically better pain and functional improvement than the other group ${ }^{[42]}$. Although there are studies comparing PRP treatment with different agents in knee OA, there are very few publications in the literature comparing OT. In 2018, In 2018, Gaballa et al. in one study, to the patients determined with knee OA a total of 2 doses of PRP injections were administered to one group every 2 weeks, and to other group a total of 4 doses of OT administered once a week, and both VAS scores and WOMAC scores improved in both groups in the first and third months after treatment. In the PRP group, there was a statistically significant improvement compared to the ozone group ${ }^{[43]}$. There are other studies supporting this result ${ }^{[44-46]}$. Duymus et al. in a study with 102 patients with mild to moderate knee OA, intraarticular PRP in the first group, hyaluronic acid in the second group, OT in the third group and VAS and WOMAC scores were found to be improved in three groups in the first month and improvement in the prp group was applied only in the 12th month. ${ }^{[47]}$. Shen et al. Similarly, in a study performed by him, placebo was superior to OT, HA and cortic osteroid injections in terms of functional recovery of PRP injection ${ }^{[48]}$. In our study, although we found improvement in both groups after treatment compared to pretreatment, we found a statistically significant decrease in VAS and WOMAC pain, physical function and total scores in PRP treatment compared to pretreatment in knee OA treatment compared to OT. While intraartricular ozone injection in knee OA treatment, which is mostly seen in obese patients in the elderly, is beneficial in reducing the pain level in patients who do not have adequate clinical response to conservative treatments, its long-term efficacy is not known. Prospective long-term follow-up studies are needed to better demonstrate the efficacy of ozone in the treatment of knee OA.

\section{Conclusion}

In conclusion; this study confirms that OT, which has been used frequently in medicine in recent years, is beneficial in terms of pain 
and functional recovery in the treatment of knee OA, and contributes to the literature in terms of limited literature on this issue. However, our study shows that the results of PRP treatment are superior to OT in terms of pain and functional limitation in the treatment of knee OA. Limitations of our study; limited number of patients and limited follow-up to a short period of 1 month after treatment, and no comparison of long-term effects.

\section{Acknowledgements}

None

\section{Role of funding source}

None

\section{Conflict of interest}

All authors have nothing to declare.

\section{References}

[1] Felson DT, McLaughlin S, Goggins J, LaValley MP, Gale ME, Totterman S, et al. Bone marrow edema and its relation to progression of knee steoarthritis. Ann Intern Med. 2003; 139: 330-6.

[2] Pelletier JP, Martel-Pelletier J, Abramson SB. Osteoarthritis, an inflammatory disease: potential implication for the selection of new therapeutic targets. Arthritis Rheum. 2001; 44: 1237-47.

[3] Felson DT, Chaisson CE, Hill CL, Totterman SM, Gale ME, Skinner KM, et al. The association of bone marrow lesions with pain in knee osteoarthritis. Ann Intern Med. 2001; 134: 541-9.

[4] Hill CL, Gale DG, Chaisson CE, Skinner K, Kazis L, Gale ME, et al. Knee effusions, popliteal cysts, and synovial thickening: association with knee pain in osteoarthritis. J Rheumatol. 2001; 28: 1330-7.

[5] Hill CL, Gale DG, Chaisson CE, Skinner K, Kazis L, Gale ME, et al. Periarticular lesions detected on magnetic resonance imaging: prevalence in knees with and without knee symptoms. Arthritis Rheum. 2003; 48: 2836-44.

[6] Felson DT. The sources of pain in knee osteoarthritis. Curr Opin Rheumatol. 2005; 17: 624-8.

[7] Wyke B. The neurology of joints: a review of general principles. Clin Rheum Dis. 198; 57: 233-9.

[8] Pelletier JP, Caron JP, Evans C, Robbins PD, Georgescu HI, Jovanovic D, et al. In vivo suppression of early experimental osteoarthritis by interleukin-1 receptor antagonist using gene therapy. Arthritis Rheum. 1997; 40: 1012-9.

[9] Greenwald RA. Oxygen radicals, inflamation, and arthritis: pathophsiological considerations and implications for threathment. Semin Arthritis Rheum. 1991; 20: 219-40.

[10] Regan EA, Bowler RP, Crapo JD. Joint fluid antioxidants are decreased in osteoarthritic joints compared to joints with macroscopically intact cartilage and subacute injury. Osteoarthritis Cartilage. 2008; 16: 515-21.

[11] Felson DT. Osteoarthritis. Rheum Dis Clin of North America. 1990; 16: 499-512.

[12] Atay T, Aslan A, Baydar ML, Ceylan B, Baykal B, Kırdemir V. Gonartrozlu hastalarda artroskopik debridman sonrası viskosüplemantasyon uygulamalarının karşılaştırılması. Acta Orthop et Traumatol Turc. 2008; 42: 228-33.

[13] Ostałowska A, Nowak D, Święchowicz S, Birkner E, Brenk A, Kasperczyk S, et al. Assessment of knee function and biochemical parameters of articular fluid and peripheral blood in gonarthrosis patients following intra-articular administration of hyaluronic acid. Pol Orthop Traumatol. 2013; 78: 173-81.

[14] Cheng OT, Souzdalnitski D, Vrooman B, Cheng J. Evidence-based knee injections for the management of arthritis. Pain Med. 2012; 13:n740-53. https://doi.org/10.1111/j.1526-4637.2012.01394.x

[15] Marx RE. Platelet-rich plasma (PRP): what is PRP and what is not PRP? İmplant Dent. 2001; 10: 225-8. http://dx.doi.org/10.1097/00008505-200110000-00002

[16] Dhillon RS, Schwarz EM, Maloney MD. Platelet-rich plasma therapy-future or trend? Arthritis Res Ther. 2012; 14: 219. http://dx.doi.org/10.1186/ar3914

[17] Al-Jaziri AA, Mahmoodi SM. Pain killing effects of ozone-oxygen injection on spine and joint osteoarthritis. Saudi Med J. 2008; 29: 553-7.

[18] Camelia C, Madalina I, Tatiana M, Marilena P, Oana A.The role of ozone therapy in maintaining the articular function and in relieving the pain for patients with knee osteoarthritis. ARS Medica Tomitana. 2014; 20: 25-9.

[19] Mishra SK, Pramanik R, Das P, Das PP, Palit AK, Roy J, et al. Role of intra-articular ozone in osteo-arthritis of knee for functional and symptomatic improvement. Ind $\mathbf{J}$ Phys Med Rehabil. 2011; 22: 65-9.

[20] Tüzün EH, Eker L, Aytar A, Daşkapan A, Bayramoğlu M. Acceptability, reliability, validity and responsiveness of the Turkish version of WOMAC osteoarthritis index. Osteoarthritis Cartilage. 2005; 13: 28-33.

[21] Sánchez M, Fiz N, Azofra J, Usabiaga J, Aduriz Recalde E, Garcia Gutierrez A, et al. A randomized clinical trial evaluating plasma rich in growth factors (PRGF Endoret) versus hyaluronicacid in the short-term treatment of symptomatic knee osteoarthritis. Arthroscopy. 2012; 28: 1070-8. https://doi.org/10.1016/j.arthro.2012.05.011

[22] Spaková T, Rosocha J, Lacko M, Harvanová D, Gharaibeh A, et al. Treatment of knee joint osteoarthritis with autologous platelet-rich plasma in comparison with hyaluronic acid. Am J Phys Med Rehabil. 2012; 91: 4117. https://doi.org/10.1097/PHM.0b013e3182aab72

[23] Woodell-May JE, Pietrzak WS. Platelet-rich plasma in orthopaedics. In: Pietrzak WS, ed. Orthopedic Biology and Medicine: Muskuloskeletal Tissue Regeneration. Totawa, NJ: Humana Press; 2008: 547-68. https://doi.org/10.1007/978-1-59745-239-7_26

[24] Baksh N, Hannon CP, Murawski CD, Smyth NA, Kennedy JG. Platelet-rich plasma in tendon models: a systematic review of basic science literature. Arthroscopy. 2013; 29: 596-607.

[25] Anitua E, Andia I, Ardanza B, Nurden P, Nurden AT. Autologous platelets as a source of proteins for healing and tissue regeneration. Thromb Haemost. 2004; 91: 415 .

[26] Graziani F, Ivanovski S, Cei S, Ducci F, Tonetti M, Gabriele M. The in vitro effect of different PRP concentrations on osteoblasts and fibroblasts. Clin Oral Implants Res. 2006; 17: 212-9. 
[27] Martinelli N, Marinozzi A, Carni S, Trovato U, Bianchi A, Denaro V. Platelet-rich plasma injections for chronic plantar fasciitis. Int Orthop. 2013; 37: 839-42.

[28] Maffulli N, Del Buono A. Platelet plasma rich products in musculoskeletal medicine: any evidence? Surgeon. 2012; 10: 148-50.

[29] Guler O, Mutlu S, Isyar M, Seker A, Kayaalp ME, Mahirogullari M. Comparison of short-term results of intraarticular platelet-rich plasma (PRP) and hyaluronic acidtreatments in early-stage gonarthrosis patients. Eur $\mathbf{J}$ Orthop Surg Traumatol. 2015; 25: 509-13. https://doi.org/10.1007/s00590-014-1517-x. Epub 2014 Aug 2.

[30] Cerza F, Carnì S, Carcangiu A, Di Vavo I, Schiavilla V, Pecora A, et al. Comparison between hyaluronic acid and platelet-rich plasma, intraarticular infiltration in the treatment of gonarthrosis. Am J Sports Med. 2012; 40: 2822-7. https://doi.org/10.1177/0363546512461902. Epub 2012 Oct 25

[31] Bocci V, Luzzi E, Corradeschi F, Paulesu L, Di Stefano A. Studies on the biological effects of ozone: 3. An attempt to define conditions for optimal induction of cytokines. Lymphokine Cytokine Res. 1993; 12: 121-6.

[32] Iliakis E, Valadakis V, Vynios DH, Tisiganos CP, Agapitos E. Rationalization of the activity of medical ozone on intervertebral disc: a histological and biochemical study. Riv Neuroradiol. 2001; 14: 23-30.

[33] Li JH, Zhou LX, Li GY, Cheng B. Treatment of middleaged and aged patients with knee osteoarthritis of yangdeficiency induced cold-damp syndrome by ozone combined Chinese materia medica: a clinical research. Zhongguo Zhong Xi Yi Jie He Za Zhi. 2013; 33: 471-5.

[34] Daif ET. Role of intra-articular ozone gas injection in the management of internal derangement of the temporomandibular joint. Oral Surg Oral Med Oral Pathol Oral Radiol. 2012; 113: 10-4.

[35] Sagai M, Bocci V. Mechanisms of Action Involved in Ozone Therapy: Is healing induced via a mild oxidative stress? Med Gas Res. 2011; 20: 29.

[36] Bocci V, Borrelli E, Travagli V, Zanardi I. The ozone paradox: ozone is a strong oxidant as well as a medical drug. Med Res Rev. 2009; 29: 646-82.

[37] Viebahn-Hänsler R, León Fernández OS, Fahmy Z. Ozone in medicine: The low-dose ozone conceptguidelines and treatment strategies. Ozone Sci Eng. 2012; 34: 408-24.
[38] Bocci VA. Scientific and medical aspects of ozone therapy. State of the art. Arch Med Res. 2006; 37: 42535 .

[39] Benvenuti P. Oxygen-Ozone Treatment of the Knee, Shoulder and Hip. A Personal Experience. Rivista Italiana di Ossigeno-Ozonoterapia 2006; 5: 135-44.

[40] Rabago D, Mundt M, Zgierska A, Grettie J. Hypertonic dextrose injection (prolotherapy) for knee osteoarthritis: Long term outcomes. Complement Ther Med. 2015; 23: 388-95.

[41] Cardelli R, De Santis F, Dall'olio M, Leonardi M. Osteoarthritis of the hip treated by intra-articular infiltration of oxygen-ozone and hyaluronic acid (Hyalubrix ${ }^{\circledR}$ ). International Journal of Ozone Therapy. 2008; 7: 66-9.

[42] Xu Feng, Li Beiping, J Clin Diagn Res. 2017; 11: 01-03.

[43] Nahla M.Gaballa, Yassir A.Mohammed, Lamiaa M.Kamel, Heba M.Mahgoub. Therapeutic efficacy of intra-articular injection of platelet-rich plasma and ozone therapy in patients with primary knee osteoarthritis. The Egyptian Rheumatologist. 2019; 41: 183-7.

[44] K.V. Chang, C.Y. Hung, F. Aliwarga, T.G. Wang, D.S. Han, W.S. Chen. Comparative effectiveness of plateletrich plasma injections for treating knee joint cartilage degenerative pathology: a systematic review and metaanalysis. Arch Phys Med Rehabil. 2014; 95: 562-75.

[45] C. Meheux, P.C. McCullioch, D.M. Lintner, K.E. Varner, J.D. Harris. Efficacy of intra-articular plateletrich plasma injections in knee osteoarthritis: a systemic review Arthroscopy. 2016; 32: 495-505.

[46] A.B. Laudy, E.W. Bakker, M. Rekers, M.H. Moen. Efficacy of platelet-rich plasma injections in the knee: a systemic review and meta-analysis. Br J Sports Med. 2015; 49: 657-72.

[47] T.M. Duymus, S. Mutlu, B. Dernek, B. Komur, Aydogmus S, Kesiktas FN. choice of intra- articular injection in treatment of knee osteoarthritis: platelet- rich plasma, hyaluronic acid or ozone options. Knee Surg Sports Trumatol Arthrosc. 2017; 25: 485-92.

[48] L. Shen, T. Yuan, S. Chen, X. Xie, C. Zhang. The temporal effect of platelet-rich plasma on pain and physical function in the treatment of knee osteoarthritis and meta-analysis of randomized controlled trials. J Orthop Surg Res. 2017; 12: 16. 